\section{Assessing the health and hygiene performance of apartment buildings}

\author{
D.C.W. Ho, H.F. Leung, \\ S.K. Wong, A.K.C. Cheung, \\ S.S.Y. Lau, W.S. Wong, \\ D.P.Y. Lung and K.W. Chau
}

\section{The authors}

More information about the authors can be found at the end of this article.

\section{Keywords}

Health and safety, Hygiene,

Performance measurement (quality), Buildings, Hong Kong

\section{Abstract}

The recent global outbreak of Severe Acute Respiratory Syndrome has aroused public concern on environmental health and hygiene. Develops a practical assessment scheme for assessing the health and hygiene performance of apartment buildings in Hong Kong. The scheme involves assessing a hierarchy of building factors that have a bearing on environmental qualities, and thus occupants' health. Proposes an index method to integrate the assessment outcomes into a simple and user-friendly performance indicator for public consumption. The index can inform the public of the health and hygiene risk of different buildings and facilitate building owners, developers, and government bodies to make more informed and socially responsible decisions on environmental health and hygiene improvement. Although the assessment scheme is tailored for the institutional and cultural settings of Hong Kong, the assessment framework for the development of the scheme is also applicable to other cities.

\section{Electronic access}

The Emerald Research Register for this journal is available at www.emeraldinsight.com/researchregister

The current issue and full text archive of this journal is available at

www.emeraldinsight.com/0263-2772.htm

Facilities

Volume $22 \cdot$ Number $3 / 4 \cdot 2004 \cdot$ pp. 58-69

(C) Emerald Group Publishing Limited · ISSN 0263-2772

DOI 10.1108/02632770410527789

\section{Introduction}

The outbreak of Severe Acute Respiratory Syndrome (SARS) in several Asian countries and Canada in 2003 has aroused public concern over environmental health and hygiene. Although the exact cause of the disease has not yet been found, SARS is known to spread quickly in densely-populated areas. Environmental factors such as dried-up U-traps and narrow re-entrants were identified as the possible causes of mass infection in multi-storey buildings (Department of Health, 2003; WHO, 2003). This triggers widespread concern over the health and hygiene conditions of the living environment, particularly in densely populated areas. In fact, the concern also extends to other infectious diseases and health problems that are closely related to the built environment (e.g. building-related illness, sick building syndrome). After the SARS crisis, more people have become aware of the importance of the environment to their health.

The authors would like gratefully to acknowledge the financial support given to this project by The University of Hong Kong SARS Fund. They also thank the representatives from the Asian Institutes of Intclligent Buildings, Chartered Institute of Housing, Chartered Institute of Building (Hong Kong Branch), Hong Kong Institute of Real Estate Administrators, Hong Kong Associate of Property Management Companies Limited, Hong Kong Institute of Architects, Hong Kong Institute of Engineers, Hong Kong Institute of Facility Management, Hong Kong Institute of Housing, Hong Kong Institute of Landscape Architects, Hong Kong Institute of Surveyors, Professional Green Building Council, Urban Renewal Authority, Chinese University of Hong Kong, City University of Hong Kong and The Hong Kong Polytechnic University for their helpful comments and participation at various stages of the project. They would also like to give special thanks to the Buildings Department and the Office of Home Affairs Department of the Government of the Hong Kong Special Administrative Region for their speedy provision of information and support. Last but not least, the authors are indebted to their colleagues in the Faculty of Architecture, Faculty of Engineering and Faculty of Medicine of The University of Hong Kong. The list of names is too long to be included here. 
In view of the growing awareness of environmental health, this paper proposes a simple and practical assessment framework to classify apartment buildings in respect of health and hygiene. The proposed framework has several key features. First, it considers a set of building-related factors that are conducive not only to infectious diseases such as SARS, but also to health problems such as chronic diseases and various types of stress. Second, it adopts a low cost, objective, and pragmatic approach so that mass assessments can be made within a short period of time. In general, only observable characteristics of buildings are acquired, measured, and assessed. Third, the framework allows for the transformation of technical assessment results into a user-friendly indicator for public consumption. Based on the indicator, the public can easily assess the relative performance of building in respect of safe-guarding the health and hygiene of the occupants. It is envisaged that the owners, the potential buyers or tenants will refer to the $\mathrm{BHHI}$ in making decisions on selling, buying or renting their property.

Apart from being a performance indicator, the BHHI should have a labelling effect to the building with high $\mathrm{BHHI}$ value. As opposed to renovating the lobby or repainting the external wall of the building, the improvement works on health and hygiene are not readily observable, so the owners are reluctant to expedite money in this respect. With the $\mathrm{BHH}$ scheme, the owners can request a re-assessment once the improvements have been made. A consequential higher BHHI reviews to the public the "hidden improvement" which would translate into higher property value. With the financial impact, the owners would have the incentive to improve the health and hygiene condition of the property as they will see the return, through increase in the property value, on the money they invested on improvement works, particularly on the management aspect.

The paper is organized as follows. We start with a discussion about what a healthy building should be. Then we outline the assessment framework for the health of apartment buildings. In the assessment framework, we define a set of assessment principles, identify the environmental qualities that affect occupants' health, and convert them into a hierarchy of building factors. After this, we integrate the assessment framework by constructing a health and hygiene index for buildings that is capable of being used by the general public. We also outline a feedback mechanism that can be used to validate the index and assessment framework based on property market data. The last section concludes by discussing the practical implications and setting out a research agenda for building health and hygiene, as well as overall building quality.

\section{What is a healthy building?}

The World Health Organization (WHO)

(1946) defined health as:

... a state of complete physical, mental and social well-being and not merely the absence of disease or infirmity.

By implication, a healthy building is a built environment that encourages positive well-being of human beings. Rousseau and Wasley (1997) identified several dimensions of positive well-being, which include lighting, air, thermal comfort, aural comfort, spaces, colour, and texture. They suggested that a healthy building should optimize these dimensions for occupants. Levin (2000) broadened Rousseau and Wasley's definition by taking the social impacts of buildings on the external environment into account. Apart from quantifiable physical dimensions, Samuelsson (2000) also stressed the importance of subjective elements such as aesthetic, job satisfaction, and social relationships in healthy buildings.

As far as the literature on building health is concerned, it seems that the term "healthy buildings" is not as popular as its counterpart "sick buildings". This is possibly because sickness has more identifiable characteristics than health. In general, sick buildings refer to buildings that cause occupants to suffer from various symptoms, such as building-related illness (BRI) and sick building syndrome (SBS) [1]. BRI is caused by specific sources like asbestos, radon, and carbon monoxide. SBS is more mysterious because its exact causes are unknown. Many studies found that SBS was 
associated with indoor air quality and psychological factors (Hedge, 1998). In particular, Finnegan et al. (1984) showed that SBS was more frequently found in mechanically ventilated buildings than naturally ventilated ones. As a result, most research focuses on air-conditioned commercial buildings and ignores apartment buildings, which predominates as the residence of choice in high-density cities and metropolitan areas such as Hong Kong.

We define apartment buildings as multi-storey buildings with multiple dwelling units and co-owned common areas. The health of apartment buildings should not be overlooked, especially when we recognize that the "home office" will be the future trend. Workers are expected to be exposed longer to their living environment and thus be more susceptible to the health and hygiene conditions of apartment buildings. In general, building assessment schemes for offices (e.g. Rider Hunt Group, 1991; Isaacs et al., 1994)[2] are not directly applicable to apartments because these two types of buildings have different settings of design and management. For instance, the problems of HVAC systems in office buildings do not apply to naturally-ventilated apartment buildings. Conversely, the use of windows for ventilation in apartment buildings creates other building design problems. Therefore, in terms of community health management, it is useful to develop an assessment scheme specifically for apartment buildings.

\section{The assessment framework}

This section describes our assessment framework for apartment buildings in respect of health and hygiene. The assessment framework is divided into three levels. The first level is a vision, which sets the assessment principles and delimits the scope of assessment. The second level assumes a strategic role, which defines the environmental qualities that contribute to occupants' health. It provides a general framework for the assessment of apartment buildings. The third level deals with operational issues. It transforms the environmental qualities into a hierarchy of building factors to be assessed, giving rise to a location-specific and time-specific assessment scheme.

\section{Principles}

Our assessment framework is developed primarily for public health management of a city or a district. It is intended for the first-tier screening of buildings' health. To achieve this aim, the assessment framework must allow for a wide coverage of buildings within a short period of time. Accordingly, the assessment framework is designed with respect to the following principles:

- Generality. The assessment framework is capable of being applied to most apartment buildings, be they low-rise or high-rise. It should have considered all possibilities that can arise in apartment buildings at present or in the near future.

- Objectivity. The factors to be assessed should be measurable and verifiable so as to minimize the amount of subjectivity. If subjective judgements cannot be avoided, they should be validated by documentary evidence (e.g. record photos, occupant's surveys).

- Practicability. Assessment methods should be simple and the factors to be assessed should be easily acquired. Since it is impractical to seek the consent of every owner to inspect the interior of their dwelling units, on-site inspection should be confined to common areas and the external environment. The interior of individual dwelling units should only be assessed based on the information in the approved plans which can be obtained from the buildings department.

- Relevance to health. The factors to be considered are those directly related to the health and hygiene of the occupants, users, and visitors. Issues such as safety, security, energy conservation, etc. are excluded.

\section{Environmental qualities}

Environmental qualities are the essential strategic elements that should be achieved for a healthy building. They make up a general assessment framework that is applicable to all apartment buildings. Based on the usual settings of apartment buildings, we identified 
eight key environmental qualities that contribute to occupants' health (Figure 1):

(1) Density. High population density implies more frequent contacts among people. This may have a negative impact on their health. First, more contacts among people increases the chance of transmission of infectious diseases. Second, reduced personal private space creates a stressful and overcrowding environment. Studies showed that population density, especially persons per room, significantly affected mortality rates (Galle et al., 1972).

(2) Air. Poor indoor air quality is known to have links with health problems such as BRI and SBS (Gots, 1998). Outdoor air pollutants such as nitrogen dioxide, sulphur dioxide, photochemical oxidants, and airborne diseases enter apartment buildings through windows. Many studies found that levels of outdoor air pollutants affected housing values (e.g. Zabel and Kiel, 2000). There are also a number of indoor air pollutants caused by occupants' activities (e.g. carbon dioxide, tobacco smoke), consumer products (e.g. volatile organic compounds), furniture (e.g.

formaldehyde), and building materials (e.g. radon, asbestos). Since the interior of individual dwelling units is not inspected, locating the source of indoor air pollutants is difficult. However, ventilation can help

Figure 1 Environmental qualities of a healthy apartment building: a general framework

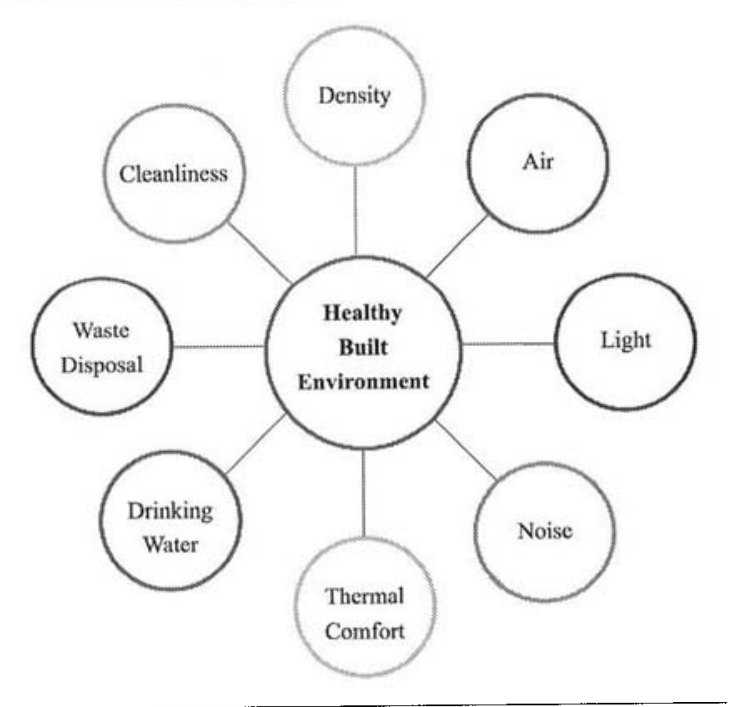

reduce indoor air pollutants. Therefore, natural ventilation is an important factor in determining indoor air quality.

(3) Light. Artificial light and daylight are two sources of light in apartment buildings. Since the interior of individual dwelling units is not inspected, our interest is not so much in brightness and glare but in the provision and penetration of daylight (Steemers, 1993). Daylight gives the tenants a sense of contact with the outdoor environment, a lack of which is found to produce suppressed feelings (Johnson et al., 1991, pp. 21-2).

(4) Noise. In apartment buildings, noise mainly comes from traffic, aircraft, construction sites, and activities in adjacent buildings. Noise generated from building services is relatively minor and negligible. Very high noise levels, prolonged exposure to noise, and noise during sleep may cause irritation, mental stress, and even hearing loss (Johnson et al., 1991, pp. 19-21). A number of studies also found that aircraft noise had a negative effect on housing values (e.g. Espey and Lopez, 2000).

(5) Thermal comfort. Thermal conditions affect the comfort of occupants. Very low humidity may irritate throat and nasal membranes, while very high humidity may induce the growth of fungi (Gots, 1998). Room temperature also affects comfort, but a consensus on the "best" temperature is still lacking. In general, since indoor thermal conditions can be controlled individually (e.g. by clothing, heater, cooler), thermal comfort depends not so much on the settings of apartment buildings, but on the external climate.

(6) Drinking water. The quality of drinking water in apartment buildings is affected by the conditions of the fresh water supply systems. Poor design or maintenance of water pipes, tanks and pumps may cause unusual odour, discolouration (e.g. due to the rusting of pipes), and contamination of water. The Environmental Protection Agency (EPA) (1999) identified 87 contaminants that may pose acute or chronic health problems. There was also evidence showing that poor drinking water 
quality depressed property values (Des Rosiers et al., 1999)

(7) Waste disposal. In apartment buildings, there are solid wastes like household refuse and fluid wastes like human excretion. It is important to discharge them properly because wastes may contain pathogens and emit undesirable odours. They also attract pests (e.g. cockroaches, mosquitoes, rodents, and houseflies) that carry and transmit pathogens to human beings.

(8) Cleanliness. The cleanliness of common areas in apartment buildings and their immediate neighbourhood reflect their environmental hygiene conditions. An unhygienic environment not only creates nuisances to occupants, it is also conducive to pest problems and the growth of micro-organisms, which lead to the spread of infectious diseases.

\section{Building factors}

To qualify as a healthy apartment building, its settings should take the above eight environmental qualities into account. For instance:

- a healthy building should not be too densely populated;

- its window design and layout should facilitate natural ventilation and penetration of daylight;

- it should be isolated from noise and air pollution sources;

- its water supply and waste discharge systems should be properly installed, maintained, and managed; and

- its environmental conditions should be clean and hygienic.

To come up with a practical assessment scheme for classifying buildings in terms of their health and hygiene performance, we need to translate the environmental qualities into a list of building specific attributes or building factors that are, as far as possible, objectively measured. In addition, the data required to measure these factors should be readily available or able to be obtained relatively easily from various sources or site inspection. For illustrative purposes, a list of building factors that are relevant to the eight environmental qualities is shown in Table I. It should be noted, however, that the list is by no means exhaustive or universally applicable because building factors are likely to be city and time-specific. The list should be compiled with reference to the institutional settings, culture, and technology of a city at a particular point in time.

For the purpose of developing an operational assessment scheme for quantifying the health and hygiene performance of a building, it would be useful to represent the performance of building factors from a building perspective by re-grouping the building factors into various parts of the built environment. We have therefore developed a hierarchy of relevant building factors as shown in Figure 2. At the top the hierarchy is the built environment, which is divided into "design" and "management" in the second level. The "design" aspect of a building represents the "hardware" of a building, which is usually hard to change technically or economically once a building is put into use. On the other hand, the "management" aspect of a building represents the "software", which is dynamic and relatively easier to change even after a building has been occupied. The classification of building factors into "design" and "management" has the advantage of dividing the factors into groups that are within and beyond the control of the owners. This helps the owners to identify what possible actions can be taken to improve their building performance. For those factors that are absolutely unchangeable by the owners, the BHHI can still be used by the government (e.g. the Urban Renewal Authority) to identify the obsolescent or derelict buildings and prioritize the urban renewal programs. Since poor health and hygiene performance of a building does not only affect its tenants, but would also have rippling effects on the community, in very serious and extreme cases, there may be a case for government intervention (e.g. compulsory remedial works or loan and subsidies for such work). The assessment scheme was designed after an intensive workshop with expert representatives from the key relevant professional bodies and other universities.

Under "design", building factors are divided into three categories (architecture, building services, and external environment), which in turn are sub-divided into 16 sub-categories. 
Table I List of building factors that affect environmental qualities (for illustrative purpose only)

\begin{tabular}{|c|c|c|c|c|c|c|c|}
\hline 1. Density & 2. Air & 3. Light & 4. Noise & $\begin{array}{l}\text { 5. Thermal } \\
\text { comfort }\end{array}$ & $\begin{array}{l}\text { 6. Drinking } \\
\text { water }\end{array}$ & 7. Waste & 8. Cleanliness \\
\hline $\begin{array}{l}\text { No. of rooms per flat } \\
\text { No. of lifts per flat } \\
\text { No. of flats per storey } \\
\text { No. of flats per } \\
\text { building } \\
\text { District population } \\
\text { density } \\
\text { Open space provision } \\
\text { (e.g. balcony, sky } \\
\text { garden, park, } \\
\text { landscape area) }\end{array}$ & $\begin{array}{l}\text { Window size } \\
\text { Cross-ventilating } \\
\text { windows } \\
\text { Headroom } \\
\text { Re-entrant shape } \\
\text { Direct air } \\
\text { pollution source } \\
\text { (e.g. highway, } \\
\text { tobacco smoking) } \\
\text { Local air quality }\end{array}$ & $\begin{array}{l}\text { Window size } \\
\text { Size of external } \\
\text { obstruction (e.g. } \\
\text { adjacent building, } \\
\text { advertisement } \\
\text { sign) } \\
\text { Proximity of } \\
\text { external } \\
\text { obstruction }\end{array}$ & $\begin{array}{l}\text { Window material } \\
\text { Noise barrier } \\
\text { provision } \\
\text { Direct noise } \\
\text { source (e.g. } \\
\text { highway, aircraft } \\
\text { path) }\end{array}$ & $\begin{array}{l}\text { Local relative } \\
\text { humidity } \\
\text { Urban heat } \\
\text { Island effects }\end{array}$ & $\begin{array}{l}\text { Pipe material } \\
\text { Frequency of } \\
\text { inspection of } \\
\text { plumbing system } \\
\text { Frequency of } \\
\text { cleaning of water } \\
\text { tanks } \\
\text { Frequency of } \\
\text { testing of water } \\
\text { sample }\end{array}$ & $\begin{array}{l}\text { Refuse chute } \\
\text { provision } \\
\text { Frequency of } \\
\text { refuse disposal } \\
\text { Route of refuse } \\
\text { disposal } \\
\text { Open hoppers for } \\
\text { waste pipe } \\
\text { Drainage location } \\
\text { Drainage } \\
\text { condition } \\
\text { Integrity of pipe } \\
\text { connection }\end{array}$ & $\begin{array}{l}\text { Frequency of } \\
\text { cleaning of } \\
\text { common areas } \\
\text { Air-conditioning } \\
\text { condensate drain } \\
\text { provision } \\
\text { Frequency of pest } \\
\text { control } \\
\text { Service lane } \\
\text { provision } \\
\text { Incompatible use } \\
\text { in the } \\
\text { neighbourhood } \\
\text { (e.g. car repair) }\end{array}$ \\
\hline
\end{tabular}

Note: Some strategic building management factors apply to all environmental qualities and are not shown in the table. They include management organization (e.g. deeds governing common areas, owner's corporations, and property management companies), documentation (e.g. keeping of building records), emergency preparedness (e.g. plan for emergency situations, provision of contingency funds), and evaluation systems (e.g. occupant survey)

Figure 2 Hierarchy of building factors

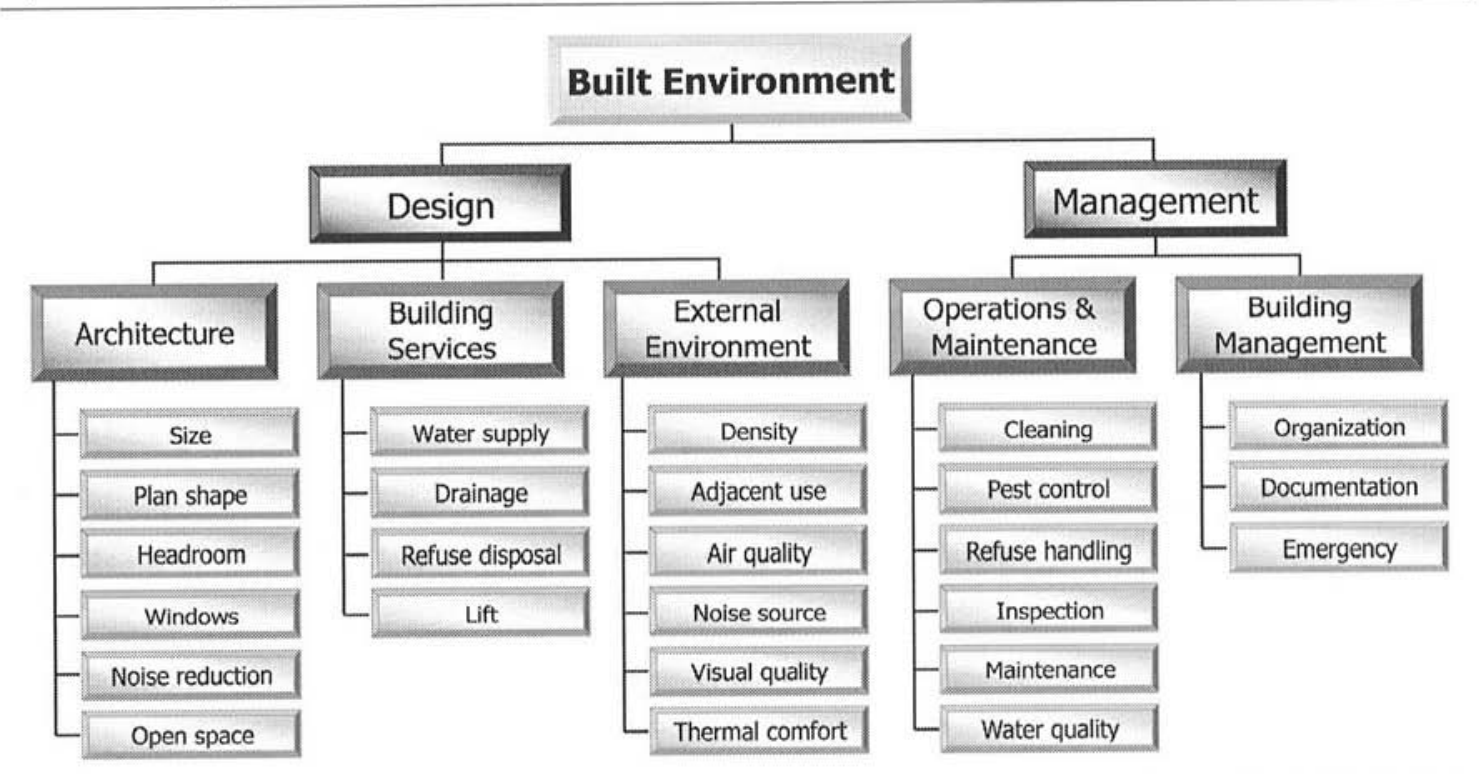

Architecture is assessed to differentiate the layout design of the subject building in promoting good lighting, efficient ventilation, noise reduction, adequate headroom, and reasonable juxtaposition of various features on plan. The presence of open space is considered a good attribute in terms of health and hygiene. The design of building services such as water supply, drainage, refuse disposal, and lift systems will be decisive on the standards of hygiene for the occupants. A "green" external environment will enhance the health of the occupants in the immediate neighbourhood. Items such as the presence of parks and amenities, population densities, and the air/aural/visual/thermal environment will be assessed. The design aspect of the scheme allows for an assessment of buildings at the design stage before construction, and can be employed as a useful checking tool by designers to improve the health and hygiene conditions of buildings in the surroundings. 
Under "management", building factors are divided into two categories (operations and maintenance and building management), which in turn are sub-divided into nine sub-categories. Operations refers to standards of cleaning, pest control and refuse handling conditions, whereas maintenance refers to the inspection and maintenance of various building services (water supply and drainage), all of which are crucial to safeguarding the health and hygiene of occupants. Building management is concerned with strategic issues such as management organization, documentation, emergency preparedness, and evaluation systems. These are forward-looking measures for enhancing the health and hygiene performance of a building.

The difference between Table I and Figure 2 is how the building factors are grouped. In Table I, the building factors are classified by environmental qualities. In Figure 2, the building factors are classified by the respective building specific attributes in a hierarchal manner. The hierarchal representation facilitates the assessment of the relative importance of the building factors using the analytical hierarchy process or AHP (Saaty, 1982), which is essential for the construction of a single measure of the performance of the health and hygiene of a building (see the following section). It reveals explicitly the human dimensions of the building that contribute to environmental qualities. This assessment scheme also allows the building factors to be compared across different buildings. Building owners and facility managers can make use of this information to identify the specific building factors that require improvement.

\section{Health and hygiene index for buildings}

The assessment scheme presented above allows facility managers and building owners to assess the health and hygiene performance of each attribute of their buildings. However, it may still appear too technical or complex for the general public, who may simply want a simple figure to represent the overall health and hygiene performance. It is therefore useful to summarize the information in the scheme by an index.
The index is essentially an aggregate figure of the ratings $(F)$ and weightings $(w)$ of all building factors:

$$
\mathrm{BHHI}=g\left(w_{1}, w_{2}, \ldots, w_{n} ; F_{1}, F_{2}, \ldots, F_{n}\right),
$$

where BHHI is the health and hygiene index for buildings; $w_{i}(i=1,2, \ldots, n)$ denotes the non-negative weighting of the $i$ th building factor and all $w_{i}$ s sum to unity; $F_{i}$ denotes the (standardized) rating of the $i$ th building factor; $n$ is the total number of building factors; and $g($.) is a continuous or discrete function that combines all $w_{i} \mathrm{~s}$ and $F_{i} \mathrm{~s}$, such as the weighted arithmetic mean[3]:

$$
\mathrm{BHHI}=\sum_{i=1}^{n} w_{i} F_{i} .
$$

Since the weightings are positive, equation (2) implies a positive relationship between BHHI and each $F_{i}$. This means that a higher $F_{i}$ (i.e. a healthier building factor) will result in a higher BHHI, holding other $F_{j} \mathrm{~s}(\forall j \neq i)$ constant. Given the functional form in equation (2) and the values of $F_{i}$ as determined by the assessment framework, the remaining unknown that needs to be ascertained is $w_{i}$.

Weightings represent the relative importance of a building factor in respect of health and hygiene. In the absence of objective empirical evidence (such as relative impact of user or expert opinions), the simplest way is to use the assessment agent's own estimates by a simple checklist system. In view of the high number of the factors involved in Figure 2, it will be difficult for the expert to give consistent weighting to each of the factor. Therefore, even though this simple system is practicable, the reliability of the results is highly questionable. Another drawback of this method is that an expert's subjective assessment may be biased by his/her experience, perception, training, and professional background. Such biases can be minimized by using the subjective weighting factors from a group of experts with diverse experience and professional backgrounds. Therefore, the use of a questionnaire survey to collect expert opinions has been a commonly adopted approach (e.g. Baum, 1993; Baird et al., 1996; Bender et al., 1999; Ho, 1999).

Among many different kinds of multiple-criteria analysis techniques, the 
analytic hierarchy process (AHP) developed Saaty (1982)[4] was selected to calculate the weightings. It is noted that other multiplecriteria analysis techniques may have a better theoretical foundation than AHP, e.g. the multi-attribute utility theory (von Neumann and Morgenstern, 1947; Savage, 1954).

Nevertheless, even in its simplest version, the assessment process is still too complicated to operate and the time and resources required are not always available. One the other hand, one of the major attractions of AHP is the use of pair-wise comparison between factors. This form of data input is generally accepted as straightforward and convenient. The AHP is particularly useful when there are a large number of factors which can be structured into a hierarchical manner (e.g. the hierarchy of factors in Figure 2). Therefore, with the consideration of the balance between practicability and academic vigour, the weightings of factors for the BHHI are at best analysed by the AHP.

The authors have conducted a survey in the form of a workshop where 35 representatives from different professional bodies and universities were given brief instructions and questionnaires. We also gave a clear definition of the key terms in the questionnaires and allowed participants to ask questions to iron out any ambiguities. We consider these procedures necessary, as respondents must have a common understanding of the questions before the results can be analysed in a meaningful way. The respondents' subjective weightings of the different factors were extracted from a pair-wise comparison of the relative importance of every pair of factors on the same level of the hierarchy (Figure 2) using the AHP computer package Expert Choice 2000 2nd Edition. The detailed procedures of the workshop are shown in Table II.

If any respondent failed to give a set of relatively consistent results under the category level, his/her response for that category would be discarded. This is a relatively expensive way of collecting information, but it would greatly improve the reliability of the weights, which is one of the most crucial aspects of the assessment framework.

During the workshop, there were 19 out of 35 sets of survey results ( 54 per cent) that were consistent for all five categories, and 15 sets (43 per cent) which were consistent in at least one category. Only one response ( 3 per cent) was discarded due to the problem of inconsistency for all of the categories. The weights of each building factor can then be computed by averaging out the weights obtained from the consistent responses (Table III).

The results showed that design (weight $=53.57$ per cent) is only slightly more important than management (weight $=46.43$ per cent). In other words, both the building designer and the property manager have important roles to play in providing a healthy and hygienic built environment.

Under the category level, operations and maintenance $($ weight $=27.08$ per cent $)$ and external environment (weight $=15.77$ per cent) were perceived as the most and least important areas that affect the health and hygiene performance of apartment buildings respectively. Whereas the weights for remaining three categories, architecture ( 18.51 per cent), building services (19.29 per cent) and building management (19.34 per cent), are all close to 20 per cent, so these categories are comparable to each other. For all of the 25 building factors, the range of the weights is between 1.38 per cent (i.e. open space) and 7.92 per cent (i.e. organisation).

Within the sub-categories of architecture, open space (weight $=1.38$ per cent) is the least important factor among all of the 25 building factors. Windows (weight $=5.70$ per cent ) is the dominant factor in this category, as the weights for other factors are below 3.50 per cent.

Most of the building factors under the category of building services are important to building health and hygiene, as three out of four factors are globally ranked within top ten most important factors. The second most important factor, drainage (weight $=6.81$ per cent), is also under building services. The sole factor ranked out of ten is lift (weight $=2.20$ per cent).

All but one building factor under the category of external environment weighed below 3.00 per cent, and were perceived as not being that important as compared to other health and hygiene attributes. That is why external environment is the least important area at the category level. Nevertheless, the respondents also recognised that air quality (weight $=5.21$ 
Table II Procedures of the AHP workshop

\begin{tabular}{|c|c|}
\hline Step & Procedure \\
\hline Step 1 & The respondent fills in the questionnaire \\
\hline tep 2 & $\begin{array}{l}\text { The questionnaire results are keyed into a laptop computer by research assistants while the respondents are } \\
\text { having a coffee break }\end{array}$ \\
\hline Step 3 & $\begin{array}{l}\text { The ranking, weighting and internal consistency ratios are calculated by the research assisants using the } \\
\text { computer package Expert Choice } 2000 \text { 2nd Edition }\end{array}$ \\
\hline Step 4 & The analysed results, i.e. the weighting and the ranking of each factor, are reported to the respondent \\
\hline Step 5 & $\begin{array}{l}\text { If the internal consistency ratio in any category level is not lower than } 0.1 \text { (this is the accepted level of } \\
\text { internal consistency as suggested by Saaty (1982)), the computer package will locate the likely source of } \\
\text { inconsistency. Without influencing the respondent's decision, the respondent is allowed to revise their } \\
\text { response either following the suggestion of the computer package or filling in the questionnaire again }\end{array}$ \\
\hline Step 6 & $\begin{array}{l}\text { The revision is keyed into a laptop computer. An instantaneous feedback on the internal consistency ratio is } \\
\text { shown to the respondent }\end{array}$ \\
\hline Step 7 & $\begin{array}{l}\text { If the internal consistency ratio is still not lower than } 0.1 \text {, the respondent can follow Steps } 5 \text { and } 6 \text { again for } \\
\text { further revision. The process will continue until the respondent does not wish to make any further changes }\end{array}$ \\
\hline
\end{tabular}

Table III Summary of global weights for the health and hygiene attributes

\begin{tabular}{|c|c|c|c|c|}
\hline Category & Sub-category & Global weights (\%) & Ranking & Useable responses \\
\hline \multicolumn{5}{|c|}{ Architecture (category weight $=18.51$ per cent) } \\
\hline & Size & 2.53 & 19 & 26 \\
\hline & Plan shape & 3.48 & 14 & 26 \\
\hline & Headroom & 2.04 & 21 & 26 \\
\hline & Windows & 5.70 & 4 & 26 \\
\hline & Noise reduction & 3.38 & 15 & 26 \\
\hline & Open space & 1.38 & 25 & 26 \\
\hline \multicolumn{5}{|c|}{ Building services (category weight $=19.29$ per cent) } \\
\hline & Water supply & 5.57 & 6 & 30 \\
\hline & Drainage & 6.81 & 2 & 30 \\
\hline & Refuse disposal & 4.71 & 9 & 30 \\
\hline & Lift & 2.20 & 20 & 30 \\
\hline \multicolumn{5}{|c|}{ External environment (category weight $=15.77$ per cent) } \\
\hline & Density & 1.93 & 22 & 24 \\
\hline & Adjacent use & 1.67 & 23 & 24 \\
\hline & Air quality & 5.21 & 7 & 24 \\
\hline & Noise source & 2.54 & 18 & 24 \\
\hline & Visual quality & 1.62 & 24 & 24 \\
\hline & Thermal comfort & 2.80 & 17 & 24 \\
\hline \multicolumn{5}{|c|}{ Operations and maintenance (category weight $=27.09$ per cent) } \\
\hline & Cleaning & 5.12 & 8 & 31 \\
\hline & Pest control & 3.08 & 16 & 31 \\
\hline & Refuse handling & 4.63 & 10 & 31 \\
\hline & Inspection & 4.55 & 13 & 31 \\
\hline & Maintenance & 4.04 & 12 & 31 \\
\hline & Water quality & 5.67 & 5 & 31 \\
\hline \multicolumn{5}{|c|}{ Building management (category weight $=19.34$ per cent) } \\
\hline & Organisation & 7.92 & 1 & 26 \\
\hline & Documentation & 6.79 & 3 & 26 \\
\hline & Emergency & 4.63 & 11 & 26 \\
\hline
\end{tabular}


per cent) is not negligible and is ranked seventh among all building factors.

The weights of building factors in operations and maintenance range from 3.08 per cent (i.e. pest control) to 5.67 per cent (i.e. water quality). This weight difference ( 2.59 per cent) is the least at the category level, meaning that the experts' perception of the importance of building factors in this category were very close to each other.

There are only three factors under the category of "building management", and they are all critical factors to building health and hygiene. Among them, organisation (weight $=7.92$ per cent) and documentation (weight $=6.79$ per cent) are globally ranked as the first and the third important factors respectively. The least important factor in building management is emergency (weight $=4.63$ per cent), which is ranked 11 th, but that is more important than half the 25 building factors.

When all $w_{i} \mathrm{~s}$ and $F_{i} \mathrm{~s}$ are found, the overall index, BHHI, can be computed. This index summarizes the relative importance and performance of all the building factors of a building. A healthier building will get a higher value for BHHI, and vice versa. If the BHHI figure is still not user-friendly enough, it can be further simplified into discrete grades such as Grade A, B, C, etc. Based on the index or grades, the general public can be better informed of the performance of buildings in respect of health and hygiene.

\section{Validation}

The idea of using the BHHI to inform the public about the health and hygiene performance of a building is based on the premise that the $\mathrm{BHHI}$ introduces new information, and that such information encapsulates specialised knowledge that was not available in the past. Since health and hygiene are valuable attributes that would command a higher price, other things being equal, one possible way of testing the validity of the assessment scheme for which the BHHI is based is to observe whether the BHHI values have been reflected in market prices after they have been publicized for some time (say three to five years). The value of the health and hygicne performance of a building as reflected by its BHHI value can be estimated using a hedonic pricing model (e.g. Chau et al., 2003). The model is an economic analysis of property transactions that measures the implicit effect of the BHHI on property prices, with other things being equal. The validity of the assessment scheme is confirmed if a property with a higher $\mathrm{BHHI}$ is transacted at a higher price, with other things being equal. This shows that the health and hygiene premium is an important indicator of the people's awareness of the health and hygiene aspects of built facilities in a city. If the test results are not as predicted, the index is not serving its purpose and a more critical review of the earlier stages of the works is necessary.

\section{Conclusion}

This paper develops an assessment framework for the health and hygiene performance of apartment buildings. The framework is essentially a strategic tool to provide useful information on buildings' health and hygiene performance, which is beneficial to various parties. At the operational level, a practical assessment scheme is developed to rate the health and hygiene performance of a building using an index (BHHI). For the building users and occupants, the assessment scheme provides a useful tool for the evaluation of different aspects of the building that affect the health and hygiene performance of their working or living environment. For developers and building owners, the assessment scheme encourages the construction and maintenance of healthy buildings. For the architects and designers, this presents a useful tool for checking and improving the quality of health and hygiene aspects of new building designs. For the government, the results of the BHHI can be used as one of the criteria for implementing urban renewal and/or mandatory inspection, maintenance, and rehabilitation schemes. Therefore, the results of implementing the assessment scheme are of significant value to the community, the profession and the government.

The paper also sets out several research directions for mass building assessments. First, large-scale building assessment based on the 
proposed framework is envisaged. It can be used to survey the health and hygiene performance of buildings in a city or district. Second, more research should be carried out to validate the assessment framework. Validation can be conducted using social science tests (e.g. property price analysis), engineering tests (e.g. direct measurement of indoor environmental quality), and/or medical tests (e.g. survey of occupant's health). Finally, if the health and hygiene assessment framework is found to be successful, the framework can be extended to other building types (e.g. offices, factories) or other building qualities (e.g. safety, functionality).

\section{Notes}

1 SBS and BRI are two related but different concepts. The Environmental Protection Agency (1991) defined SBS as "situations in which building occupants experience acute health and comfort effects that appear to be linked to time spent in a building, but no specific illness or cause can be identified", while BRI is defined as "symptoms of diagnosable illness [that] are identified and can be attributed directly to airborne building contaminants".

2 See So and Wong (2002) for a review of the historical development of building assessment methods.

3 So and Wong (2002) argued that the weighted geometric mean is more appropriate in terms of human thinking. Whether arithmetic or geometric means reflect human behaviour better is yet to be determined. Moreover, the difference between the two means tends to be practically small if no factor weights dominate others strongly.

4 See Schoemaker and Waid (1982) for a comparison of different approaches to determining weights.

\section{References}

Baird, G., Gray, J., Isaacs, N., Kernohan, D. and Mclndoe, G. (1996), Building Evaluation Techniques, McGraw-Hill, New York, NY.

Baum, A.E. (1993), "Quality, depreciation, and property performance", Journal of Real Estate Research, Vol. 8 No. 4 , pp. 541-65.

Bender, A., Din, A., Hoesli, M. and Laakso, J. (1999), "Environmental quality perceptions of urban commercial real estate", Journal of Property Investment and Finance, Vol. 17 No. 3, pp. 280-96.

Beron, K., Murdoch, J. and Thayer, M. (2001), "The benefits of visibility improvement: new evidence from the Los Angeles metropolitan area", Journal of Real Estate Finance and Economics, Vol. 22 No. 2, pp. 319-37.
Chau, K.W., Leung, A.Y.T., Yiu, C.Y. and Wong, S.K. (2003), "Estimating the value enhancement effects of refurbishment", Facilities, Vol. 21 No. 1/2, pp. 13-19.

Department of Health (2003), Main Findings of an Investigation into the Outbreak of SARS at Amoy Gardens, April, Hong Kong Government, Hong Kong, available at: www.info.gov.hk/info/ap/pdf/amoy_e.pdf

Des Rosiers, F., Bolduc, A. and Thériault, M. (1999), "Environment and value. Does drinking water quality affect house prices?", Facilities, Vol. 17 No. 5, pp. 444-63.

Environmental Protection Agency (EPA) (1991), “Sick building syndrome", Indoor Air Quality Fact Sheet \#4, EPA, Washington, DC, available at: www.epa.gov/iaq/ pubs/sbs.html

Environmental Protection Agency (EPA) (1999), Drinking Water and Health - What You Need to Know!, EPA, Washington, DC, available at: www.epa.gov/ safewater/dwhealth.html

Espey, M. and Lopez, H. (2000), "The impact of airport noise and proximity on residential property values", Growth and Change, Vol. 31 No. 3, pp. 408-19.

Finnegan, M.J., Pickering, A.C. and Burge, P.S. (1984), "The sick building syndrome: prevalence studies", British Medical Journal, Vol. 289, pp. 1573-5.

Galle, O.R., Gove, W.R. and McPherson, J.M. (1972), "Population density and pathology: what are the relations for man?", Science, New Series, Vol. 176 No. 4030 , pp. $23-30$.

Gots, R.E. (1998), "Indoor air and health: clear-cut, equivocal, and unlikely", in O'Reilly, J.T., Hagan, P., Gots, R. and Hedge, A. (Eds), Keeping Buildings Healthy - How to Monitor and Prevent Indoor Environmental Problems, Wiley, Chichester, Ch. 4, pp. 93-117.

Hedge, A. (1998), "What can we learn about indoor environmental quality concerns from studies?", in O'Reilly, J.T., Hagan, P., Gots, R. and Hedge, A. (Eds), Keeping Buildings Healthy - How to Monitor and Prevent Indoor Environmental Problems, Wiley, Chichester, Ch. 5, pp. 119-35.

Ho, D.C.W. (1999), "Preferences on office quality attributes: a Sydney CBD study", Australian Land Economics Review, Vol. 5 No. 2, pp. 36-42.

Issacs, N., Bruhns, H., Gray, J. and Tippett, H. (1994), Building Quality Assessment - Research, Development and Analysis for Office and Retail Buildings, Centre for Building Performance Research, Victoria University of Wellington, Wellington.

Johnson, B.G., Kronvall, J., Lindvall, T., Wallin, A. and Lindencrona, H.W. (1991), Buildings and Health: Indoor Climate and Effective Energy Use, Swedish Council for Building Research, Stockholm.

Levin, H. (2000), "Design and construct of healthy and sustainable buildings" in Proceedings of Healthy Buildings 2000, Helsinki, Vol. 4, pp. 13-22, available at: www.hb2000.org/workshop2.html

Rider Hunt Group (1991), Building Quality Assessment, Rider Hunt Group, Sydney. 
Rousseau, D. and Wasley, J. (1997), Healthy by Design: Building and Remodeling Solutions for Creating Healthy Homes, Hartley and Marks, Point Roberts.

Samuelsson, I. (2000), "Quality assurance of the indoor environment in schools, offices and dwellings" in Proceedings of Healthy Buildings 2000, Helsinki, Vol. 4, pp. 555-60, available at: www.hb2000.org/ workshop2.html

Saaty, T.L. (1982), The Analytical Hierarchy Process, McGraw-Hill, New York, NY.

Savage, L.J. (1954), The Foundations of Statistics, Wiley, New York, NY.

Schoemaker, P.J. and Waid, C.C. (1982), "An experimental comparison of different approaches to determining weights in additive utility models", Management Science, Vol. 28 No. 2, pp. 182-96.

So, A.T.P. and Wong, K.C. (2002), "On the quantitative assessment of intelligent buildings", Facilities, Vol. 20 No. 5, pp. 208-16.

Steemers, K. (1993), "The role of lighting in the environmental performance of buildings", Facilities, Vol. 11 No. 5, pp. 14-19.

Von Neumann, J. and Morgenstern, 0. (1947), Theory of Games and Economic Behaviour, 2nd ed., Princeton University Press, Princeton, NJ.

World Health Organization (WHO) (1946), "Preamble to the Constitution of the World Health Organization", as
Volume $22 \cdot$ Number $3 / 4 \cdot 2004 \cdot 58-69$

adopted by the International Health Conference, New York, NY, 19-22 June.

World Health Organization (WHO) (2003), WHO Environmental Health Team Reports on Amoy Gardens, May, available at: www.info.gov.hk/info/ap/ who-amoye.pdf

Zabel J.E. and Kiel K.A. (2000), "Estimating the demand for air quality in four US cities", Land Economics, Vol. 76 No. 2, pp. 174-94.

(D.C.W. Ho is Associate Professor, H.F. Leung is Associate Professor and Head, S.K. Wong is a Lecturer, A.K.C. Cheung is a PhD

Researcher, and K.W. Chau is Dean and Chair Professor, all at the Department of Real Estate and Construction, Faculty of Architecture, The University of Hong Kong, Hong Kong.

S.S.Y. Lau and W.S. Wong are Associate Professors, and D.P.Y. Lung is Professor and Head, all at the Department of Architecture, Faculty of Architecture, The University of Hong Kong, Hong Kong.) 